\title{
ESTUDIOS DE GÉNERO Y TEORÍA DE LA COMUNICACIÓN: NUEVOS TERRITORIOS Y NUEVOS RETOS
}

\author{
GENDER STUDIES AND THEORY OF THE COMMUNICATION: NEW FIELDS \\ AND CHALLENGES
}

Mercedes Arriaga Flórez

Universidad de Sevilla

\section{RESUMEN:}

En los últimos años, los estudios de género han experimentado un notable progreso y se han adentrado en nuevos terrenos que no habían sido explorados, como en la representación del cuerpo femenino. Sin embargo, todavía queda mucho camino por recorrer.

\section{Palabras claves:}

Estudios de género, mujer, cuerpo.

\section{Abstract:}

In recent years, gender studies have experienced a significant progress and have gone deep into new fields which had not been researched before, as the representation of the feminine body. However, there is still a long road ahead.

\section{KEY WORD:}

Gender studies, woman, body. 
En el museo de arte precolombino de Santiago de Chile, hay una estatuilla del siglo II después de Cristo de una mujer de barro, cuyo pubis es un gran tatuaje.

Me pareció una buena representación de cómo el cuerpo femenino, al ser un objeto de intercambio entre varones, siempre fue desde antiguo un formidable instrumento de comunicación. Un cuerpo que, como el signo de Saussure (1998), se compone de carne y mensaje, significante de piel y significado mutable. Escritura de carne, escritura divina, quizás, en un tiempo en el que las mujeres todavía eran consideradas por su trascendencia divina, puesto que traían criaturas que no eran de este mundo, como dice Luisa Muraro (1994), con una bellísima metáfora.

Si "el hombre es un símbolo", como anunciaba el famoso título del libro de Peirce (1990), entonces la mujer sería por lo menos dos signos, la dualidad que proclama Luce Irrigaray (1990), ante la tiranía del uno, único, pero yo me inclino más por un rizoma de signos, robándole el término a Deleuze (1975), una foresta enmarañada de símbolos, como representaba el pubis de mi estatuilla nasca, que en la maraña de su vello de tinta llevaba inscritos discursos, leyes, palabras, creencias, estereotipos que señalaban su cuerpo como cuerpo de mujer, es decir, no sólo en su dimensión de valor de uso, sino sobre todo como signo de relaciones sociales, como mensaje, lo que quiere decir al mismo tiempo cuerpo escrito y proscrito. Cuerpo que se ofrece y cuerpo que se niega, cuerpo que se exhibe y cuerpo que se oculta, cuerpo silenciado y cuerpo historiado, cuerpo dicho y contradicho, como dice Teresa de Lauretis del sujeto femenino (1999). Cuerpo-texto palimpsesto cuya carga semiótica van escribiendo, borrando y reescribiendo, desde las instituciones, las diferentes realidades históricosociales que se subsiguen.

Foucault señala que la historia de nuestra cultura se apoya en la valoración del cuerpo físico y simbólico, pero cuando luego estudia los saberes y los efectos de poder que actúan sobre él, lo hace tomando en consideración un cuerpo masculino, el único que cuenta en el pensamiento moral-ético-filosófico desde la Antigua Grecia al menos, y que Foucault denomina precisamente: “la historia del hombre de deseo" (2004: 12) Obviando los efectos especiales, por decirlo así, que el poder tiene reservados a los cuerpos de las mujeres. El confinamiento y la violación de las mujeres a través de los siglos, no sólo están relacionados con la historia de la locura y de los castigos (Foucault, 1979), sino también con la cancelación sistemática de la identidad personal, en el caso del confinamiento, como de la identidad personal-nacional, en el caso de la violación, cuando los cuerpos de las mujeres se vuelven territorios que conquistar y en los que plantar la propia semilla eliminando otras etnias, como nos demostró muy bien la guerra en Yugoslavia.

He empezado hablando de cuerpos para hablar de la relación entre estudios de género y de la teoría de la comunicación que a mí me interesa especialmente, es decir, la semiótica, porque, como bien anunciaba Rossi-Landi (1994) la comunicación como producción-intercambio y consumo de mercancías, de mensajes que son signos, se ha ido sofisticando y se ha ido convirtiendo, en lo visual y virtual, en producciónintercambio y consumo de cuerpos. $\mathrm{Y}$ esos cuerpos de hombres, pero sobre todo de mujeres, no se presentan muchas veces como mensajes explícitos, sino que esconden hábilmente su carga de significado, valores, ideología. Cuerpos interrogantes que se acercan a nuestros ojos "porque el deseo es una pregunta cuya respuesta nadie conoce", dice el famoso verso de Luis Cernuda, pero en este caso los constructores de imágenes del cuerpo conocen perfectamente la respuesta a nuestros deseos, es más, construyen nuestro deseo a partir de esos cuerpos, vagamente humanos, porque en la realidad son imposibles de alcanzar.

Cuerpos que son metáforas donde el término real ha sido "exterminado por su doble clonado", como dice Ida Dominijanni (Muraro, 1998: 13), y a través de la asunción de dichos cuerpos, terminamos por vivir "por interpuesta persona". Nuestros cuerpos de carne y hueso, en el circuito de la comunicación-producción de nuestro moderno sistema mundializado, deben "adaptarse" a las exigencias de mercados nuevos (cirugía, productos estéticos, comidas dietéticas, actividades deportivas, moda, relaciones públicas, etc.), que proponen modelos idénticos entre si y reproponen los mismos estereotipos de siempre, aunque bajo un aspecto más atractivo. Los medios de comunicación no sólo trasmiten la publicidad de ciertas mercancías-cuerpos, sino también la ideología que los sustenta, que no es otra que la que rige la implacable lógica del mercado de lo humano. La complicidad entre orden simbólico y el orden social queda al descubierto en esas imposiciones que se convierten en la "normalidad" de "nuestros" sueños inducidos. Y en ese proceso, tanto la semiótica como los estudios de género intentan desvelar los mecanismos de dominio, pero también los mecanismos de interiorización por parte de los individuos.

Los cuerpos de la publicidad son simulacros de cuerpos, son cárceles más que de carne, de huesos, que nos prometen la felicidad que antes corría a cargo de objetos, coches, electrodomésticos. Ahora que tenemos de casi todo, queremos un cuerpo, porque sin ese cuerpo ideal parece que todas las puertas se cierran: no vamos a ser aceptados, ni amados, ni admirados, vamos a ser invisibles, o lo que es peor aún ridiculizados, caricaturizados. Los cuerpos mensajes llaman en causa no sólo la estética, sino la ética, la política e incluso la religión, haciendo desaparecer toda referencia a la interioridad, al contenido, al significado, es decir, al humano que vive dentro de una funda de carne.

Ahora que lo tenemos todo, consumir se ha convertido en consumirse, producir en producirse a través de la cirugía y otras técnicas, e intercambiar en intercambiarse, con las posibilidades que Internet nos ofrece de hacernos pasar por quien queramos, en 
una especie de antropofagia corporal en la que mensaje y mensajero coinciden, como bien ponen de manifiesto los trabajos de Normal Baitello Junior (2002).

Si como afirma Augusto Ponzio (1994) la comunicación social no es sólo el proceso que se realiza entre un emisor y un receptor, sino el proceso que está a priori y nos señala como emisor y receptor, es decir no sólo como actuantes de un intercambio de mensajes sino, sobre todo $y$, antes que nada, como sujetos, tenemos que concluir que a lo largo de los siglos el emisor, el autor de un texto, el director de una orquesta, el inventor o descubridor de algo, siempre se ha identificado con un sujeto masculino. $Y$ que ahora con la comunicación audiovisual y virtual, a pesar de que en ella intervienen las mujeres como productoras de signos, aunque en una medida muy inferior a la de los hombres, las imágenes siguen siendo construidas desde una óptica terriblemente patriarcal y masculina. Teresa de Lauretis (1999) habla de la violencia implícita en las "prácticas de visualización" en nuestra cultura, que recae en gran parte sobre las mujeres, aunque también sobre los hombres. Y es que el sistema capitalista de consumo y comunicación no perdona a nadie, y persigue a los cuerpos que circulan como si fueran signos heréticos con consignas anatemas de forma que la "pobreza de las experiencias privadas se convierte en pobreza de las experiencias humanas", como decía Benjamín (1997). En el nuevo paisaje hedonístico de la sociedad postindustrial, el desarrollo de la personalidad, se ha convertido en el reino de la perpetuación de los estereotipos de género, de raza, de nacionalidad, de religión. Se ha convertido en un cúmulo de tópicos donde la persona no tiene cabida o viene estigmatizado con el hierro candente de lo incorrecto, insurrecto, indeseado, impertinente, excéntrico. Y me paro en esta palabra porque en ella vuelvo a reanudar las relaciones entre semiótica y estudios de género. Gian Paolo Caprettini (1998) una vez definió al semiótico como un excéntrico que se ocupa de todo y de nada, es curioso que el semiótico excéntrico coincida con el sujeto excéntrico feminista, que teorizan Teresa de Lauretis (1999) y Rosi Braidotti (1995).

Si tomamos en consideración los tres aspectos que Teresa de Lauretis señala para los estudios de género, es decir, dimensión de la identidad personal, principio de organización de la estructura social y base de los valores normativos, podemos concluir que el género es sobre todo una construcción cultural, que se alimenta en el catálogo de identidades-identificaciones del sistema de comunicación. Como señala Cristina Demaria "el género se perfila como un dispositivo semiótico que los sujetos asumen como componente de su identidad" (Demaria, 2003: 28)

El género es también un principio que organiza la comunicación social, tanto en su dimensión de lenguaje hablado como de lenguaje icónico y mediático, que está presente, además, en todos los procesos de significación y de simbolización.
Algunas de las ideas fundamentales que la teoría de la comunicación postmoderna nos ha dejado en herencia son: primero, el conocimiento es siempre de alguien, que en él proyecta su propia visión del mundo, siempre hegemónica, segundo, la comunicación es un proceso que responde a los intereses de alguien sobre alguien, sobre todo en un mundo globalizado y teleidiotizado, tercero, la masa indiferenciada que construye el lenguaje no lo hace tanto para nombrar el mundo sino para construir y mantener su poder sobre él, para legitimarse y construir su mitografía, reduciendo a los Otros, al territorio, a veces simbólico, a veces real del insulto y del silencio, es decir, a los límites de lo comunicable e incomprensible.

A estas ideas habría que añadir alguna otra que procede de los estudios de género y sirve para aclarar procesos culturales y comunicativos que, en principio, parecen naturales y son aceptados como tales, pero en realidad son construidos.

Es Bourdieu (1999: 83 e sig.) el que señalaba que la dominación masculina convierte a las mujeres en objetos simbólicos y por lo tanto en seres percibidos, seres construidos por otros, lo que las coloca en un estado permanente de inseguridad o dependencia simbólica. La dependencia simbólica de las mujeres, no es otra cosa que la necesidad de verse constantemente a través de la mirada y los valores ajenos, y su gemela, la violencia simbólica que los sistemas de comunicación ejercen, figura en la base de la violencia física, de la violencia doméstica, de la violencia de género contra las mujeres. Ahora bien, esa violencia que es la piedra del escándalo, que vende en las televisiones y revistas, que hace ganar votos fáciles a la política, esa violencia que hace enfadar al sistema, porque visualiza algo que debiera permanecer oculto, porque en la sombra de lo obvio es donde se ejerce el poder de forma más insidiosa.

Faltan leyes contra la desigualdad simbólica porque aún no tenemos una cultura que nos la haga percibir y corregir. Y ni siquiera nombrar si me apuran mucho. No sé si conocen una de las últimas noticias llegadas de la Real Academia Española, que se ha negado a incluir en la nueva edición de su diccionario, el termino estudios de género, por encontrarlo poco castellano, y que en la definición de violencia domestica reza la explicación "violencia que se ejerce en el hogar", sin decir de quien para quien, aunque luego en muchas otras ocasiones no tiene dificultades para especificar el sujeto de otras acciones, como en la definición de trapo: "su mujer lo trato como un trapo", o en la de furor que no deja de ejemplificar con "furor uterino", explicado como "insaciable deseo de hacer el amor en las mujeres". Ningún furor masculino viene ejemplificado, aunque estoy segura que es bastante frecuente y a la vista de todos. Amelia Valcárcel señalaba en una conferencia, a propósito de este argumento, que por el momento nos es imposible concebir y dar curso en nuestra comunicación al concepto de "genia". Ida Magli (1995) en uno de sus libros sobre la espiritualidad femenina ejemplifica muy bien lo que significa la desigualdad simbólica y para ello cita la escena de la vida de 
San Francisco de Asís en la que él se desnuda en la iglesia para dar a entender a sus conciudadanos que se despoja de sus bienes terrenales. Si hubiera sido una mujer ese gesto nunca hubiera tenido ese significado, ni hubiera sido percibido por la comunidad de esa forma. Los estudios de género no analizan la colocación diferente que hombres y mujeres tienen, y su repercusión en las conciencias personales, en los comportamientos, en lo cultural, lingüístico, ideológico. Pero ese análisis no sirve de nada sin un proyecto, por decirlo así, "humano" y, por lo tanto "político", en el sentido más amplio de la palabra, que proponga nuevas relaciones sociales y nuevas distribuciones no sólo de las riquezas materiales, sino, y sobre todo, de los privilegios, o sea de la igualdad de oportunidades. Por lo tanto la base teórica y filosófica de los estudios de género es humanista pero con una añadidura de pensamiento feminista que corrige la gran laguna del humanismo, al centrarse en la construcción y definición del "hombre", que no englobaba a la mujer. El pensamiento feminista del que hablo es el que se refiere a esa tradición filosófica que desde finales de la Edad Media denuncia precisamente la falacia de pensar a las mujeres como seres inferiores o copias imperfectas $\mathrm{y}$, al mismo tiempo, lucha por ampliar el concepto de lo humano para que en él tengan cabida las ideas, las creaciones, las imaginaciones, las obras de las mujeres, para que lo femenino no quede excluido ni de la civilización, ni de la cultura, ni de la libertad, igualdad y fraternidad.

Uno de los logros más importantes de los estudios de género en los últimos años es haber demostrado que la pretendida "igualdad" entre hombres y mujeres, que las leyes establecen en nuestros países, en las prácticas sociales no existe y que aún quedan muchas barreras invisibles en lo privado y en lo público que impiden a las mujeres ocupar los lugares que debieran, les impiden gozar de la misma consideración que los hombres. Y esas desigualdades están arraigadas en nuestro imaginario: en nuestro sentido de lo que valemos y de las potencialidades que podemos llegar a desarrollar como mujeres, y desde luego están arraigadas en lo que los hombres esperan, desean, pretenden de nosotras. En este sentido, los estudios de género dejan atrás la convicción de que trasformar la sociedad en sentido igualitario sea un "asunto de mujeres", para sustituirla por una crítica profunda de lo que hasta hace pocos años se consideraban las feminidades y las masculinidades, dos bloques que se daban la espalda, como un matrimonio bien avenido.

Paralelamente a la semiótica de cuño humanista, que buscan la dignidad de lo humano, advirtiendo del peligro de la alineación y de la cosificación de las personas del planeta, los estudios de género buscan la dignidad de lo femenino en un contexto cultural mundial donde las mujeres no tienen aún derechos de ciudadanía.

Ambos, semiótica y estudios de género, más que definir escuelas o sistemas, construcciones, son herramientas críticas, lecturas del mundo, que parten del principio del análisis de los signos-cuerpos como plenamente objetivos, puesto que están insertados en una realidad histórico-social. Ambos parecen operar con las mismas categorías: la contradicción de Roland Barthes (1997), la retórica de la sospecha, la heterodoxia, la dialogía de Bajtín, lo sobredicho y los significados añadidos de Rossi Landi (1992). Ambos buscan el sentido obtuso de las cosas, como diría el gran maestro Barthes, y ese sentido se encuentra precisamente en la zona excéntrica que Teresa de Lauretis señala para la epistemología feminista.

Ambos dan una importancia vital al proceso hermeútico, a la visión interdisciplinar, a una epistemología abierta y no cerrada.

Es decir ambas disciplinas trabajan contra lo obvio, detectan estructuras de poder e intereses donde solo parecía haber la naturalidad de las cosas que pasan, las cosas que son así como son y a las que hay que resignarse, o lo que es peor, adaptarse.

Los estudios de género utilizan el análisis semiótico como base operativa, para detectar como dice Umberto Eco (1990) las técnicas con las que se construye la ideología que es siempre, no lo olvidemos, ideología del patriarcado.

Los estudios de género, como los estudios semióticos, son una frontera que avanzan sobre territorios no explorados aún, Elena Gajeri, sostiene que los estudios de las mujeres y los estudios de género representan la verdadera frontera del saber contemporáneo (Gajeri, 1999: 296). En este sentido son, como dice Lotman (1998), “un mecanismo que crea un nuevo pensamiento al traducir a la cultura lo que permanecía intraducible, indiferenciado, obvio, inasequible, invisible y eso los convierte en un pensamiento utópico, en el que está implicado el Tercero ausente de Bajtín (1988) es decir, la verdad futura.

\section{RefERENCIAS Bibliográficas}

Baitello Junior, Norval, “A iconofagia e a Antropofagia: As imagens que nos devoram”, Comuniquiatra 5, Sevilla, http: //www.comuniquiatra.dk3.com

Bajtin, M., L'autore e l'eroe, Einaudi, Turín, 1988.

Barthes, R., Saggi critici. L'obvio e l ottuso, Einaudi, Turín, 1982.

Benjamin, W., Sul concetto di storia, Einaudi Turín, 1997.

Bourdieu, P., La dominación masculina, Anagrama, Madrid, 1999

Braidotti, ROSI. Soggetto nomade. Feminismo e crisi della modernità. Donzelli, Roma, 1995.

Cabanilles, A., “Cultura y género”, en La conjura del olvido, Icaria, Barcelona, 1997.

Caprettini, G. P., Ordine e disordine, Meltemi, Roma, 1998.

Cavarero, A., Nonostante Platone. Figure femminili nella filosofia antica, Roma, Editori Riuniti, 1990.

De Lauretis, T., Sogetti eccentrici, Feltrinelli, Milán, 1999. 
Deleuze, G., Logica del senso, Feltrinelli, Milán, 1997.

Demaria, C., Teorie di genere. Femminismo, critica, postcoloniale e semiotica, Bompiani, Milán, 2003.

Eco, U., I limiti dell'interpretazione, Bompiani, Milán, 1990.

Foucault, M., Historia de la locura, Fondo de Cultura Económica, Madrid, 1979.

----, M., L'uso dei piaceri, Feltrinelli, Milán, 2004.

Gajeri, Elena, "Studi femminili e di genere", en Introduzione alla letteratura comparata, Mondadori, Milán, pp. 296-340, 1999.

Irigaray, L., Questo sesso che non è un sesso, Feltrinelli, Milán, 1990.

Lotman, J., Il girotondo delle muse, Moretti\&Vitali, Bérgamo, 1998.

Magli, I., De la dignidad de la mujer, Icaria, Barcelona, 1995.

Muraro, L., El orden simbólico de la madre, Horas y horas, Madrid, 1994.

----, L., Maglia o uncinetto, Manifestolibri, Roma, 1998.

Peirce, CH., Man is a sign, Mouton-De Gruyter, 1990.

Ponzio,A., “Comunicazione, migrazione, occupazione.Perunacriticadelacomunicazionemondializzata”, en Comunicazione, comunità informazione, Manni, Lecce, pp.7-24, 1996.

Calefato, P., Petrilli, S., Fondamenti di filosofia del linguaggio, Latera, Bari-Roma, 1994.

Rossi-Landi, F., Il linguaggio come mercato e come lavoro, Bompiani, Milano, 1992.

----, Semiotica e ideologia, Bompiani, Milano, 1994.

Saussurre, F., Curso de lingüística general, Alianza, Madrid, 1998. 